\title{
A Review on Device-Free Passive Indoor Positioning Methods
}

\author{
Tero Kivimäki, Timo Vuorela, Pekka Peltola and Jukka Vanhala \\ Department of Electronics and Communications Engineering, \\ Tampere University of Technology, Tampere, Finland \\ \{tero.kivimaki, timo.vuorela, pekka.peltola, jukka.vanhala\}@tut.fi
}

\begin{abstract}
There is an increasing need for unobtrusive positioning systems in smart homes and assisted living environments. This review presents the main technologies used for device-free passive indoor positioning, including pressure sensors, thermal infrared sensors, sound source localization, ultrasound, radio frequency, infrastructure-mediated sensing and electric-field-based methods. In addition, it compares the advantages and disadvantages of a range of positioning systems to help identify the most suitable positioning technology for specific cases.
\end{abstract}

Keywords: Human positioning, indoor location,pervasive positioning, smart environments, device-free positioning

\section{Introduction}

The need for positioning is obrious in smart homes and assisted living environments. Reliable location information is vital for different location-based services that make living easier and safer. For example, one service that uses location information is the automatic adjustment of lightning, heating or home electronic devices based on a user's physical location. However, as operating environments, homes place certain constraints on positioning systems. For instance, a positioning system should be extremely easy to use. In practice, the whole system shourd also be invisible to the user, as users might find even small sensors or actuators too anattractive if they are visible [1]. To be acceptable for home use, a positioning system needs to be passive device-free, and unobtrusive.

In passive positioning, users do not need to perform any specific activities for the system to position them; the systenr operates automatically so that users do not necessarily notice its presence. Device-free means that people tracked by the system do not need to carry devices or tags. This is important, as people are generally unwilling to wear extra devices, especially at home [2]. In addition, individuals can forget to put a device on, especially after changing their clothes. Another challenge is that every individual in a positioning area should have a device, which makes having visitors problematic. Furthermore, mobile positioning devices use batteries and require regular monitoring and changing.

Sone device-free passive positioning systems use cameras in their construction [3,4]. However, camera systems have several drawbacks. These systems require a line of sight from the user to the camera. Lighting can also affect the operation, and camera systems do not work at all in the dark. Moreover, video processing is expensive. The main problem, however, is related to privacy concerns. Most people are unwilling to install any system that they perceive as intrusive in their homes [5, 6]. Accordingly, this paper omits systems that use conventional cameras. 
This paper presents the main technologies that can be used in device-free passive positioning: pressure sensors (Section 2), thermal infrared sensors (Section 3), sound source localization (Section 4), ultrasound (Section 5), electric field (Section 6), infrastructuremediated sensing (Section 7), and radio frequency (RF) (Section 8). As noted, each technology has its own section. These sections do not present every system or project that uses the technology in question; instead, they provide one or a few examples, based on the number of known implementations. The presented implementations were selected based on their recognisability and the quantity and quality of the information available about the system. Section 0 describes miscellaneous forthcoming systems. Finally, Section 0 compares the presented technologies and provides a table that contrasts the main properties of each technology.

\section{Pressure Sensors}

Pressure sensors are the most traditional positioning system technology, the initial way to construct a positioning system was to install pressure-sensitive sensors on on under a floor surface. If installed under the floor surface, the sensors are invisible to the user, but the installation is laborious. This type of installation is also not always possible, as it requires flexible flooring and sufficient installation space beneath the floor surface.

One benefit of this system is that it enables user identification, as the pressure generated corresponds to a person's unique weight and gait. User identification is beyond the scope of this paper, but [7-9] provide more informationon this topic.

\subsection{Load Cell Systems}

In a load cell system, the floor onsists of tiles equipped with load cells. Normally, this system places cells under the corners of the tiles so that each load cell measures the sum of the contributions from the corners of four separate adjacent tiles. These cells sense vertical force and allow the system to determine the user's location on the floor. The location accuracy is equal to the size of the tile. For example, [10] used $50 \times 50 \mathrm{~cm}$ tiles. The algorithms needed for location tracking are quite simple and are not computationally heavy.

To make the system simple and cheaper Schmidt et al., [11] determined how to reduce the number of load cells. Their jedea was to use bigger tiles (they used a $2.4 \times 1.8 \mathrm{~m}$ tile) and to determine a person's position on a tile by calculating the centre of pressure on the surface using the load measured at each corner of the tile. Their achieved tracking accuracy was almost in the same range as when using smaller tiles. Naturally, the calculation only works if there is only one person at a time on the tile.

\subsection{Pixelated Surfaces}

Instead of using separate sensors, as in a load cell system, some systems use pixelated surfaces made up of many sensors. For example, Middleton et al.'s [7] 3.0 x 0.5 m sensor mat use 1536 individual sensors. The sensors are simple binary switches made by separating a pair of wires by a deformable material such as foam; when a user applies force to the construction, the wires come into contact. The sensor mat consists of 96 horizontal and 16 vertical wires, as shown in Figure 1.

As the sensors are binary on/off switches, this system can only detect if a person is standing on the mat. For instance, it is not able to determine the weight of the person on the mat. Furthermore, the prototype mat cost just under $€ 80$. Covering larger areas with this kind of mat would be quite expensive. 


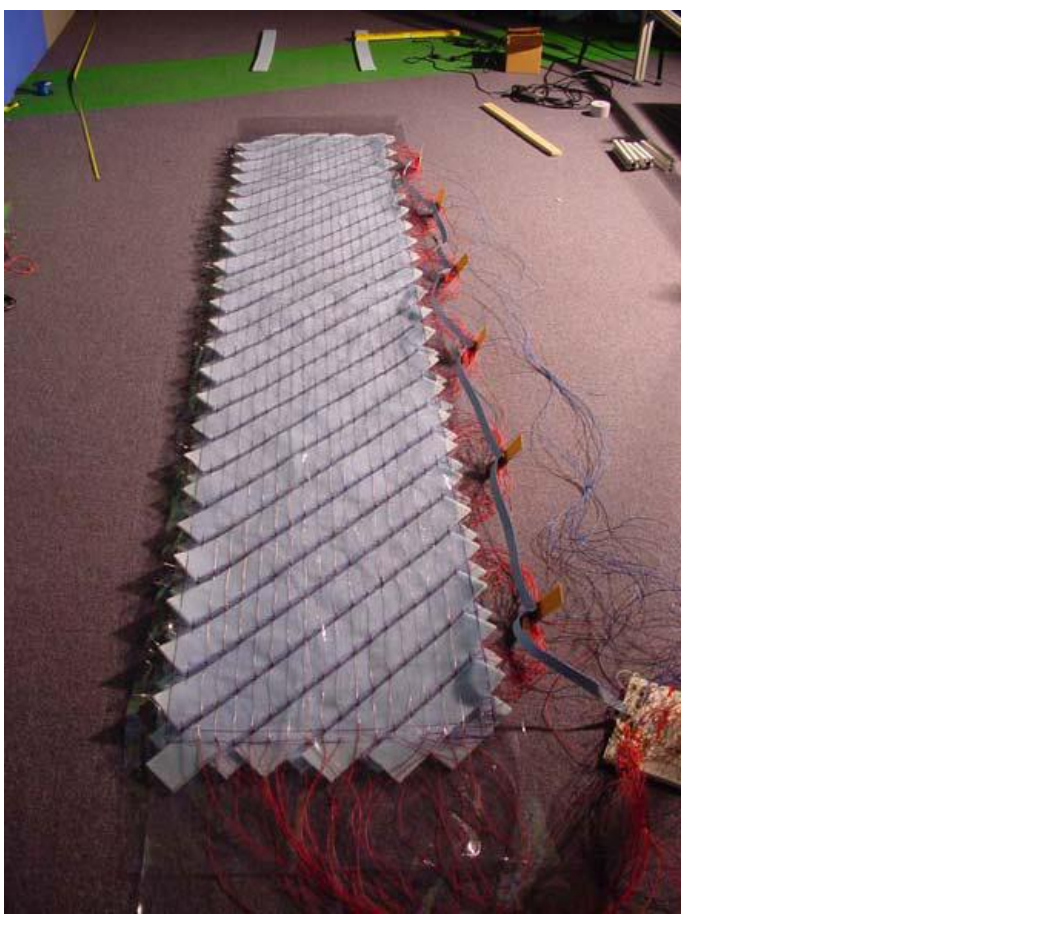

Figure 1. Sensor Ma Of Binary Switches [7]

Alternatively, the Magic Carpet [12], a $1.8 \times 3.0 \mathrm{~m}$ carpet that is similar to Middleton et al. 's, sensor mat, uses a $16 \times 32$ gridof piezoelectric wires. The type of wire used produces a voltage if pressed anywhere along its length 4 The system can determine a person's location on the carpet based on which horizontal wire and which vertical wire he or she is standing on. The size of the grid's cells - this case, $9 \times 10 \mathrm{~cm}$ - determines the system's accuracy.

Another option is electromechanical film (EMFi): a commercially available thin and flexible polypropylene film coated with metal electrodes. EMFi is capable of storing a large permanent charge. If an external orce alfects the surface of the EMFi, a change in the charge between the electrodes, detected as a voltage, occurs [13]. For example, Pirttikangas et al.'s, [9] study used a 30 x 34 EMAF sensor stripe matrix under normal flooring. These authors concentrated on identifying users, but this type of system is also suitable for positioning purposes. However, as 4 MFi only reacts to changes in pressure, it cannot be used to detect immobile persons uch as a person who has fallen to the floor and lies still.

All the above-mentioned pixelated surface systems require a lot of wiring. They are also fixed: resizing or reshaping them would require modifications to the wiring, the hardware, and the software.

Alternatively, the Z-Tile system [14] uses modular nodes that can be connected to create positioning areas of various shapes and sizes. Each node has 20 hexagonal force-sensitive resistors on its surface. Because of their shape, the nodes can interlock and be self-holding, as shown in Figure 2. 


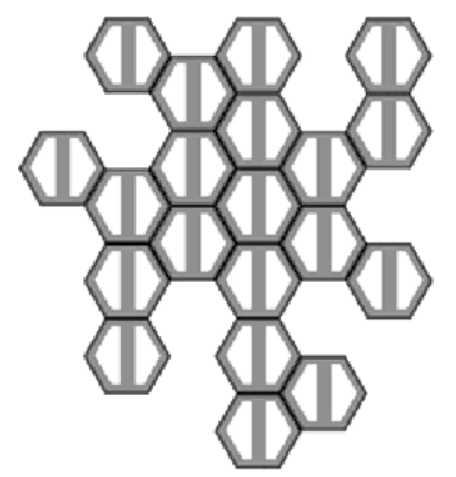

Figure 2. A single Z-Tile [14]

Moreover, the Z-Tile system does not require a separate data wire for each node. Instead, the interlocking tiles form a self-organising network. One node operates as a power source and a data gateway for the network, as Figure 3 illustrates. The main disadvantage of the system is that the volume of the data being produced by the Z-tiles is so high that the data processing is problematic if large areas would be covered with Z-tiles.

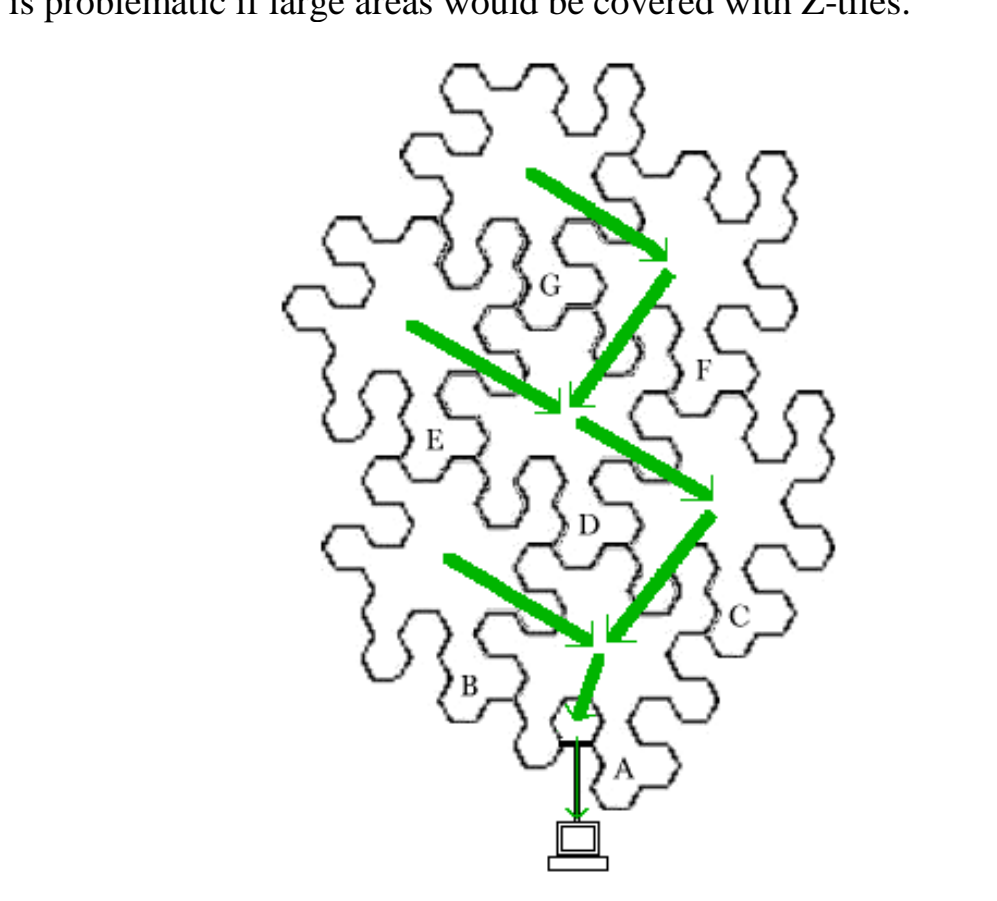

Figure 3. Data Routing in a Z-Tile Carpet [14]

Another scalable system is Smart Carpet [15]. To create a Smart Carpet, sensor electronics are embedded in textiles and woven into a carpet, as Figure 4 displays. Each node is $15 \times 15$ $\mathrm{cm}$ and operates as one plate for a capacitive sensor. Walking on the carpet activates these sensors. One can modify the shape and size of the carpet by cutting it between the nodes. 


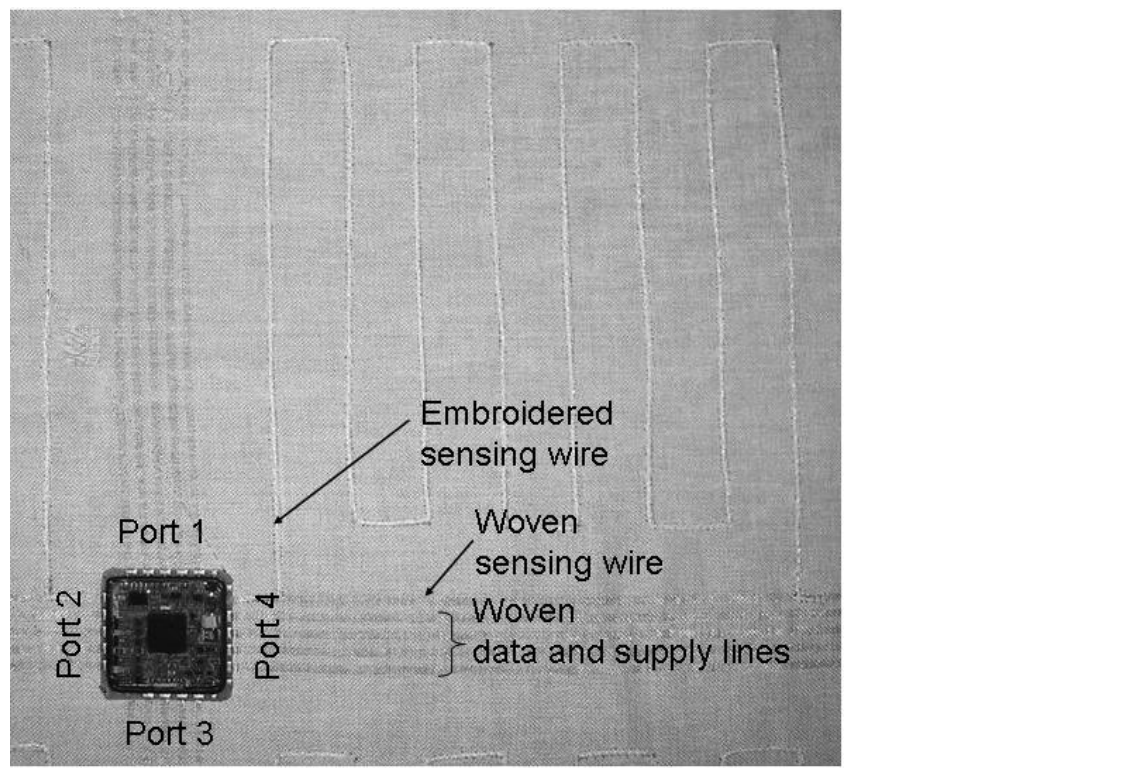

Figure 4. The Smart Carpet Sensor Node [15]

As Figure 5 illustrates, the computer that performs the position calculations connects to only one node. When a footstep activates a node that node sends a sensor activation packet to the neighbouring node, which then routes it long the shortest path to the computer.

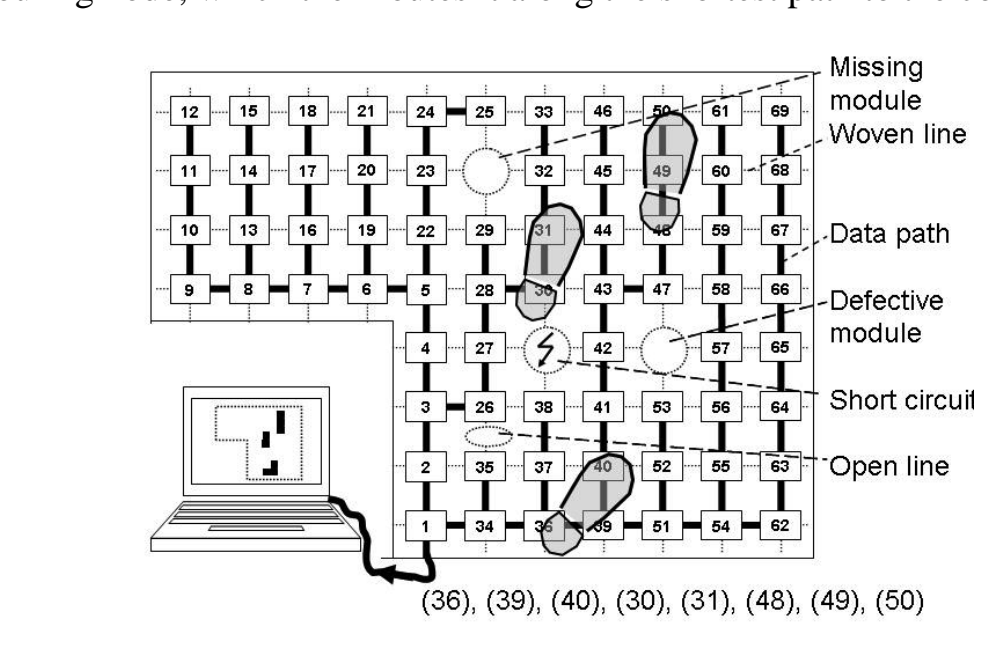

Figure 5. The Smart Carpet Structure [15]

\section{Thermal Infrared Sensors}

Infrared light is part of the electromagnetic radiation spectrum, with wavelengths from 750 $\mathrm{nm}$ to $1 \mathrm{~mm}$. The infrared spectrum further divides by wavelength into five subsections. Wavelengths from 8 to $15 \mu \mathrm{m}$ belong to the long-wavelength infrared spectrum subsection. This part of the electromagnetic spectrum corresponds to wavelengths that radiate from objects with temperatures somewhere between 0 and $70{ }^{\circ} \mathrm{C}[16]$.

Fluke Ti55/20, an infrared camera used in [17], operates in this range. The camera has an image resolution of $320 \times 240$ pixels and uses uncooled microbolometers. Microbolometers 
are tiny (down to $17 \mu \mathrm{m}$ ) infrared detectors. When a microbolometer absorbs infrared light its temperature increases as well as its electrical resistance. This change in electrical resistance can be measured to produce a thermal image from all the microbolometer cells. For instance, using this technology, [18] created a thermal image database of healthy people that researchers can use for reference in the diagnosis of various diseases or in sleep research.

The infrared cameras record the radiation at the same range as the human body emits it. Figure 6 shows the blackbody radiation curve of a human body at normal body temperature of $37^{\circ} \mathrm{C}$. One can use the blackbody radiation model to compare the thermal or electromagnetic radiation of different objects. An ideal blackbody absorbs all the radiation directed at it, but also acts as a perfect emitter.

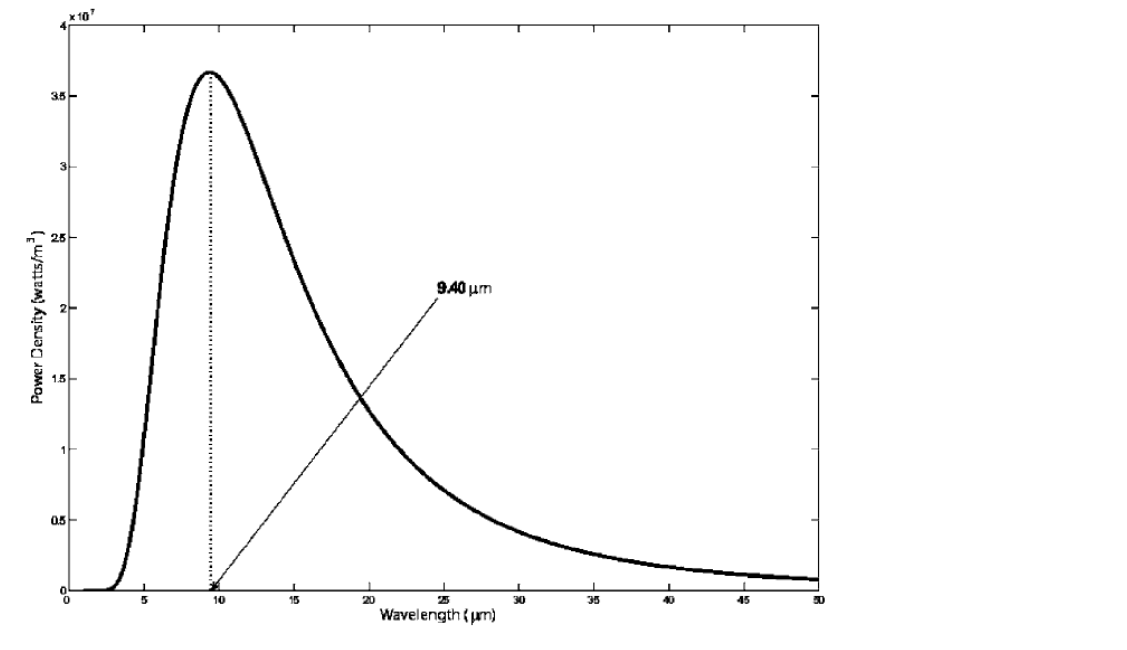

Figure 6. Blackbody Radiation Cunve of Human Body at Normal Body Temperature of $37^{\circ} \mathrm{C}[18]$

In Figure 6, the irradiation power peak is at approximately $9.40 \mu \mathrm{m}$. According to Wien's Law ([16], [20]),

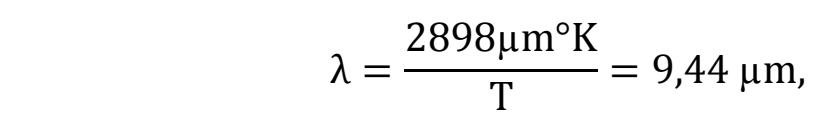

where $\mathrm{T}$ is $34{ }^{\circ} \mathrm{C}$. The above equation derives from Planck's law. So both references [16] and [20] point out that for a person with normal body temperature measured to be $37^{\circ} \mathrm{C}$, the irradiation power is at maximum approximately at the temperature of $34{ }^{\circ} \mathrm{C}$. Thus, thermal imaging devices used for human subjects should operate in this region of long-wavelength infrared light In addition, the long-wavelength infrared spectrum lies within the atmospheric window. Inside this window, the attenuation of thermal radiation in air is very low, which results ingreater contrast in the acquired image $[16,21]$.

According to the database measurements in [17], a person's head appears as the warmest part of the body in thermal images. This is even truer for positioning purposes, since other body parts are usually clothed and clothing suppresses the recorded level on the infrared image.

\subsection{Technologies}

Many thermal imaging devices use microbolometers [22]. These devices are relatively expensive. For example, the RAZ-IR Mini, the camera used in [23], costs almost $€ 8000$ [24]. 
Furthermore, quantum detectors, which use a photoelectric effect, are not very suitable for large-scale usage, because they need to cool down to $70 \mathrm{~K}$. Likewise, Golay cell technology is not suitable for large-scale usage, because it is relatively sensitive to vibrations [21]. A Golay cell is a gas-filled chamber enclosed in an infrared absorbing material and a flexible membrane. When infrared light strikes the cell, the light heats the gas, the gas expands, and the system records the membrane's movement [25]. Though these two technologies can be accurate in controlled environments, they are not that suitable for smart home environment.

Pyroelectric sensors and thermopiles are more affordable alternatives. The pyroelectric sensors detect changes in heat flow and generate electrical signals; in other words, a polarisation change and the piezoelectric effect induce an output change. Similarly, thermopiles, which consist of an active or passive thermocouple, generate signals that depend on the difference between the object and ambient infrared radiation; the Seebeck effect creates the output change. Thermopiles have a response time between 20 and 50 ms 116, 20. 21]. Honorato et al., [26] discuss the differences between thermopile and pyroelectric sensors in more detail.

Many applications also use Fresnel lenses to divide the field of view 19, 20, 27-29]. For instance, Shankar et al., [19] placed a Fresnel lens on a PIR325 pyroelectric sensor, whereas [19] and [27] used quad-type sensors. With quad sensors, the output consists of the strength of the pyroelectric/passive infrared sensor signal and the sensing element that the target activated. In [28], Yoshiike et al., constructed a pyroelectric detector array. They placed this custom-made pyroelectric rotating sensor on the ceiling. [6 [29], $\mathrm{Wu}$ and $\mathrm{Li}$ placed an additional mask on top of the lens. One car also use a lens system to control thermopiles' field of view [16].

Figure 7 demonstrates the beam division of the Eिresnellens for different sensing elements. In one sector, the further the target 18, the less accurate the measurement will be. Distance detection is effective within a range of approxinately $10.0 \mathrm{~m} \mathrm{[29].}$

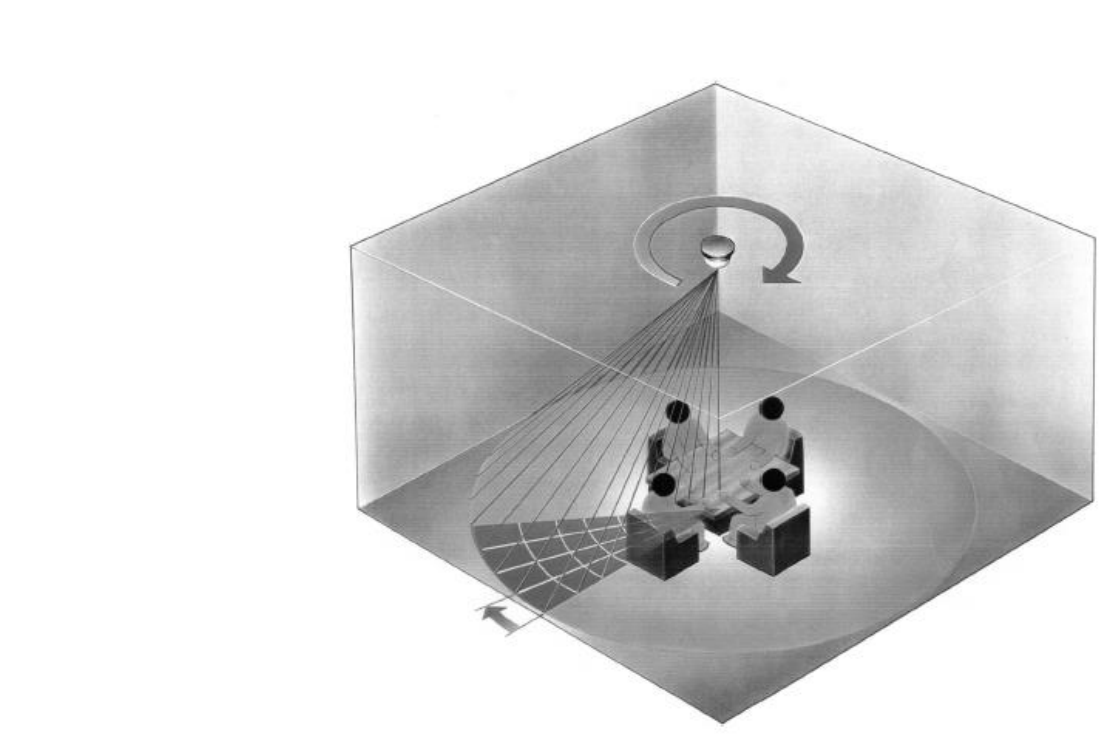

Figure 7. A Lens System Dividing the Tracking Area into Sectors [28]

\subsection{Applications}

A very attractive option in positioning is to use hybrid technologies. For instance, [30] effectively measured the occupancy of a room by combining data from pyroelectric sensors, 
carbon dioxide sensors, and relative humidity sensors. Similarly, [31] combined a thermal infrared localization (ThILo) scheme, which uses thermal sensors, with the Cricket indoor positioning system, which uses ultrasound in combination with an RF signal. However, the Cricket system uses a tag, so it is not a passive positioning system. In [32], Zhou et al., studied gait by using a pyroelectric sensor network. The drawbacks in different sensing technologies can be overcome by using simultaneously another technology.

For instance, with thermal imaging, the contrast between the target and its surroundings can change, for example, as day turns into night. This presents a challenge when analysing thermal camera images. To achieve better target recognition, Chetty [33] combined colour image data with thermal image data. She first processed the thermal image into the background and foreground layers using the expectation-maximisation algorithm. The background did not contain dynamic objects. Chetty then compared the foreground shape and appearance cues with a database of thermal images of pedestrians for exact positioning and pose.

Depending on the application and the environment, the thermal imaging system requirements are different. For indoor environment, the technology use in [23] was able to identify the warm targets in the field of view (RAZ-IR mini theymal camera) and produce a tactile feedback. This study used Brailliant 32, a tactile imager, to describe the thermal environment. With this device, a blind user can scan the imager board, which has a tactile pixelated surface, with his fingers to 'visualise' the thermal map of his surroundings.

Farhat et al., [34] presented an interesting calibration method. In their study, they calibrated the system, which measured an int a-vehicular thernal environment, using a Peltier plate. They combined the carbon dioxide-concentration arata with the thermal image data to sense the presence of people inside a vehicle.

Overall, the accuracy of the more expensive thermal camera systems is higher than that the discussed pyroelectric and thermopile applications. The angular resolution of the latter applications is often only a few degrees, and the applications mostly use the angle of arrival and triangulation in their postion derivation. The accuracy of the pyroelectric and thermopile applications is approxiniately $20 \mathrm{~cm}$, depending on the object's distance from the sensors $[16],[21,35]$.

\subsection{Context}

Unlike in nonmal images in thermal images, illumination is not a significant problem. However, metallic surfaces create difficulties, as they are good heat conductors and infrared radiation reflectors 19. Rather than simply recording the environments on stage, it can be easier and cheaper to simulate it beforehand. One can gain better understanding of these conditions by creating an infrared simulation environment using OpenGL, as the researchers did in [19] Here, the applied techniques of radiosity and ray tracing create a greater computational burden in the simulation environment, but they help to describe the real enyironment in more detail.

In thermal positioning, the sensor network fusion and data processing depend heavily on the context. The environment might have dynamic heating elements like lamps or heaters that can disrupt the thermal positioning system's performance. Thus, one should carefully consider the sensor number, type, and placement. For instance, [36] emphasised the region of interest - the section of a thermal image that has a dynamic target, like a human or a lamp. Naturally, systems need to identify and interpret all the important heat sources correctly.

Above all, multi-target tracking is perhaps the most challenging task in thermal positioning, especially with low-resolution thermal detector sensor networks. For example, it is difficult to determine the true number of people inside a room with low-resolution devices. 
Redundancy is one answer to this problem. To combine different sensor data, [36] used principal component analysis. However, algorithm development is perhaps the most important aspect of a multi-target tracking scheme. In [37], Kemper and Hauschildt highlighted the drawbacks of multi-hypothesis tracking and joint probabilistic data association filters, such as the need for a fixed number of targets. In [16], Hauschildt and Kirchhof favoured the more dynamic sequential Monte Carlo probability hypothesis density filter for multi-target tracking. With respect to future applications, the contrast invariant descriptor for thermal images presented in [22] will certainly aid multi-target tracking systems developers.

\section{Sound Source Localization}

Sound source localization methods fall into two main categories. In the first category, sometimes identified as active sound source localization, as in radar and sonar, the system sends out a pre-set signal and receives an echo signal from the target. In the second category, the system only receives target-generated signals, meaning these systens can only locate activities that produce sound [38].

The localization of a sound requires detection by a su table sensor such as a microphone. Usually, sound source localization uses a microphone array consisting of three or more microphones [39]. Microphone pairs, i.e., two microphones, can deduce the direction of a sound from the time difference in sound arrival, as presented in Figure 8. This is the time difference of arrival (TDOA) method. If sensørs in multiple locations measure the direction of a sound, the system can calculate the location of the soand source using triangulation. One can increase the accuracy of the source iocation estimation by increasing the number of microphones, as long as all the microphones and amplifiers have equal frequency characteristics [39].

Sound source localization argonthms fall into three main categories: TDOA [40], steered beamforming [41], and high-resolution spectral estimation [42]. TDOA, introduced above, is the most widely used method. Steered beamforming, or steered response power, calculates the delay value by forming summation signals of signals from two different microphones with multiple delay values. The sound source location calculation uses the delay value that maximises the summation signal, Identified here as the actual delay. High-resolution spectral estimation determines the impulse response between the sound source and the receiving microphone and uses this impulse response to estimate the time delay [42].

Indoor sound source localization faces several challenges. These challenges include background noise, reverberation (i.e., echoes), the broadbandness of sounds, movement of the sound source, and simultaneous sound sources [43]. For example, reverberation is a significant problem in TDOA analysis, as TDOA methods assume that the sound signal's route between the sound source and the recording sensor is straight, as Figure 8 demonstrates. 


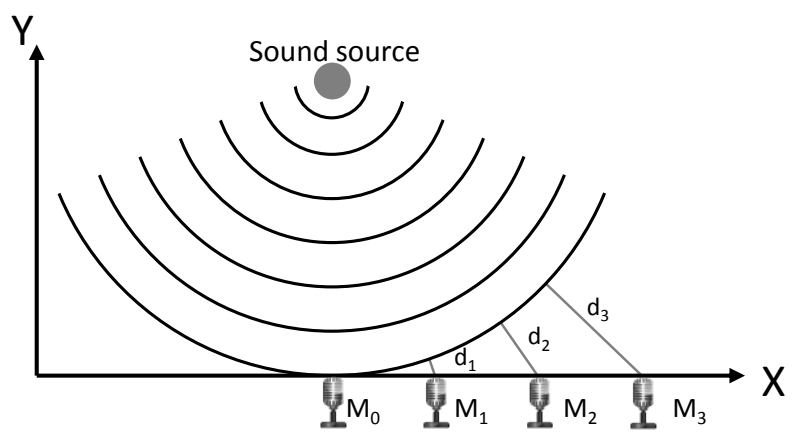

Figure 8. Wavefront Propagation From a Sound Source to a Microphone Array. The Wavefront Reaches Microphones $M_{1}-M_{3}$ with Delays $d_{1}-d_{3}$, with Respect to $M_{0}$. One can Calculate the Location of the Sound Source according to these Delays. Modified from [44] and [45]

With respect to practical applications, academic studies have used sound source localization to locate speakers in a meeting room [46-48], to detect face-to-face conversations in a home environment [43], to conduct real-time sound source localization in a hall [39], and to detect the user's position in robotic applications [49]. Another popular and well known application of sound source localization using a microphone array is Microsoft's Kinect - a motion sensing input device (http://www.micyosoft.com/en-as/kinectforwindows/).

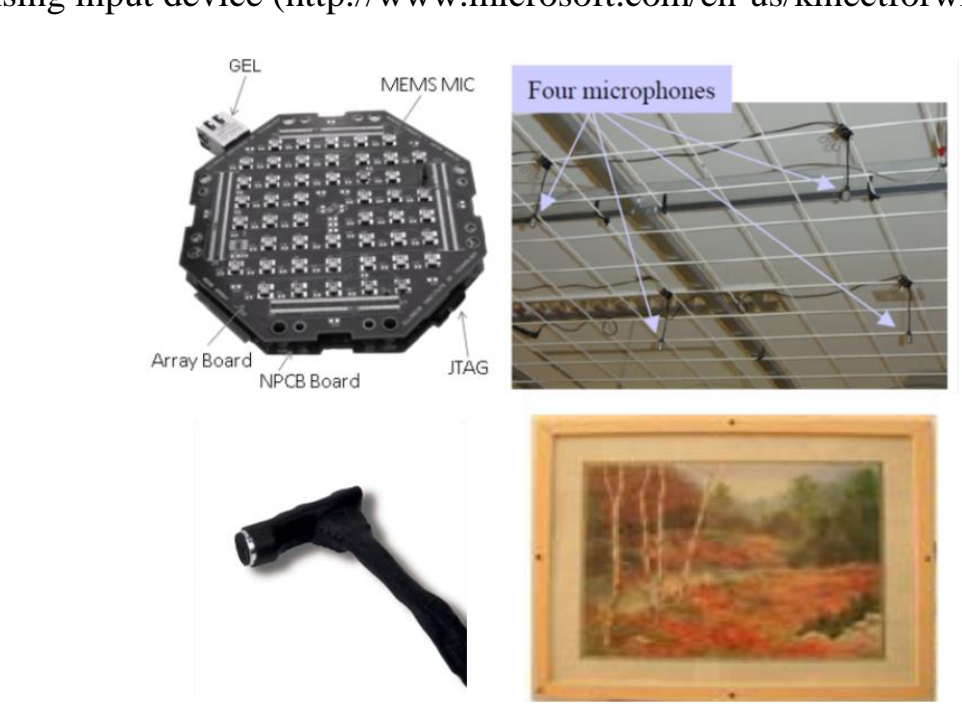

Figure 9. Nicrophone Arrays. Top Left, a Scalable Microphone Array [50]. Top Right, a Microphone Array for Detecting Footsteps [51]. Bottom Left, a Miniature Microphone. Bottom Right, a Miniature Microphone Embedded in a Frame [43]

As Figure 9 illustrates, microphone arrays can have various shapes and sizes, and small microphones can be embedded in everyday household items, such as picture frames, or in home structures, such as ceilings $[43,51]$. Embedding microphones in movable objects can make it relatively easy to install a sound source localization system in an existing household. Using wireless methods to transfer localization data between separate microphone arrays can further simplify the installation process. 
Despite the relative ease of installation, the computational burden in sound source localization is relatively high, as systems must calculate a cross-correlation between signals received by multiple microphones. However, the data throughput of a microphone array is significantly less than that of a camera-based system [43].

\section{Ultrasound}

The speed of an ultrasound wave is relatively low-about $345 \mathrm{~m} / \mathrm{s}$. Thus, one can precisely measure the time it takes an ultrasound wave to travel from one point to another [1]. There are two methods used in implementing ultrasound positioning: time of flight (TOF) and TDOA. TOF methods determine an object's position by measuring how long a signal takes to travel from the transmitter to the receiver, whereas TDOA methods determine an object's position by calculating the difference between the travel times of signals from two transmitters to the receiver. However, ultrasound positioning systems that use TDOA methods are sernsitive to noise, which can be a problem, especially at long ranges [52].

In traditional ultrasound positioning systems, individuals neêd to carry mobile receivers to be localised. However, Nishida et al., [53] have created a device-free ultrasound positioning solution. Their system employs an ultrasonic radar technology used in medical diagnosis. Transmitters generate ultrasound signals, and the system detects a person's position by receiving these signals after they reflect off the person's head and ealculating the signals' TOF.

Figure 10 demonstrates the principle of calculating the location of a person's head. One can calculate the propagation distance, L, from the TOF and the known speed of the signal. If the positions of the transmitter and receiver are known, determining the head's location is straightforward.

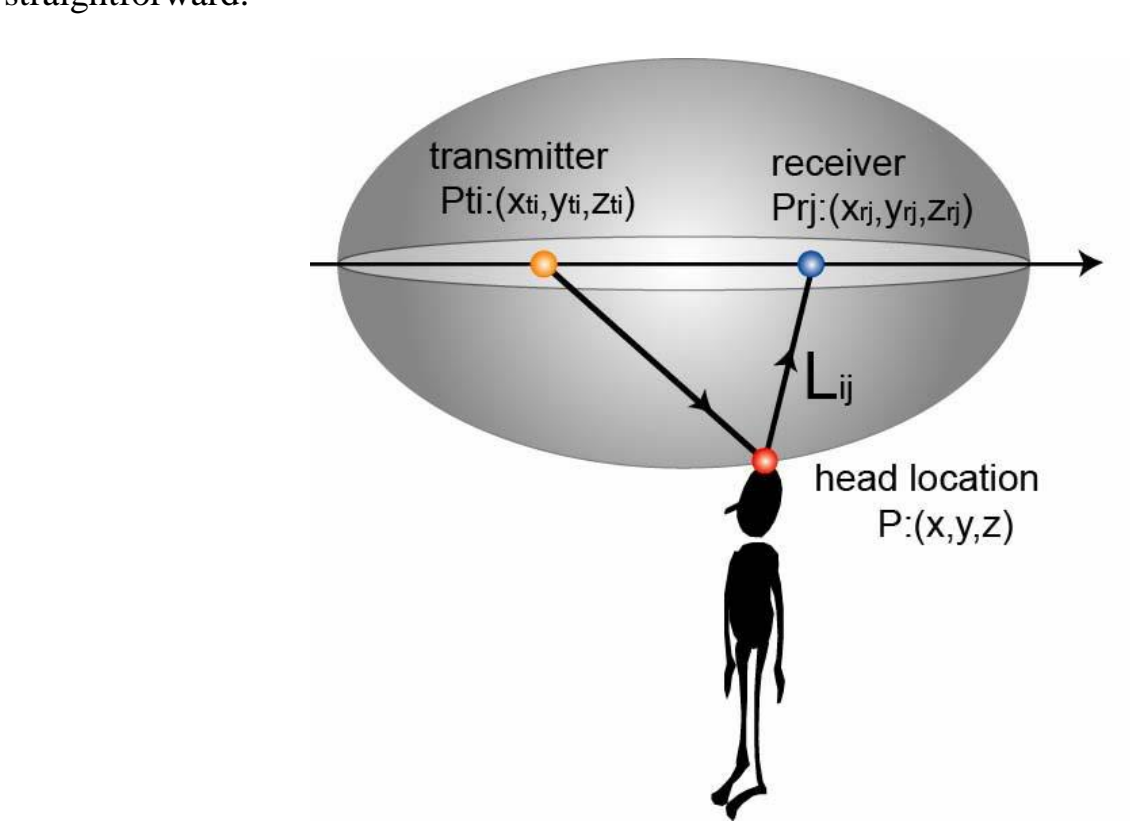

Figure 10. Principle of Calculating the Location of a Person's Head [54]

Nishida et al.'s, [53] pilot system detected both the horizontal position and vertical position of a person's head, meaning it could detect whether a person was standing or sitting, with a location detection accuracy of approximately $5 \mathrm{~cm}$. Hori and Nishida [55] successfully tested the system developed in [53] and [56] in a nursing home. They only used the system to 
monitor the position of a person's head on and around his or her bed and used other location systems elsewhere.

This system is suitable for similar applications that require accurate position information in a very small area. However, this promising system's drawback is that it requires numerous sensors. The pilot platform was $1.8 \times 1.2 \mathrm{~m}$ and had 18 transmitters and 32 receivers. Covering a whole house or an apartment would require the installation of thousands of sensors - an expensive and burdensome operation.

\section{Electric Field}

The human body conducts low-frequency signals well; this enables the electric field positioning of human beings. Zimmerman et al., [57] first introduced the idea of using electric fields to locate humans in 1995 . He presented two modes of operation for electric field localization: the human shunt and the human transmitter.

In the human shunt mode, a transmitter electrode emits an electric field and a receiver electrode senses the electric field. The potential difference between the electrodes generates a displacement current that flows from the transmitter to the recerver. When person enters this electric field, their body shunts the electric field to the ground and decreases the amount of displacement current that reaches the receiver. This decrease in displacement current is proportional to the person's proximity to the receiver.

In the human transmitter mode, the system capacitively couples a low-frequency energy to a person's body, making the body act as an electric field transmitter. The system measures the displacement current, which increases as the person moyes closer to the receiver electrode.

In 1998, Smith et al., [58] introduced Gthird operation mode: the loading mode. This mode uses only one electrode to create the electric field between the electrode and a person's body and to measure the current pulled from the transmitter into the body.

Figure 11 illustrates the three operation modes presented above. The location methods introduced later in this section are based on these modes.

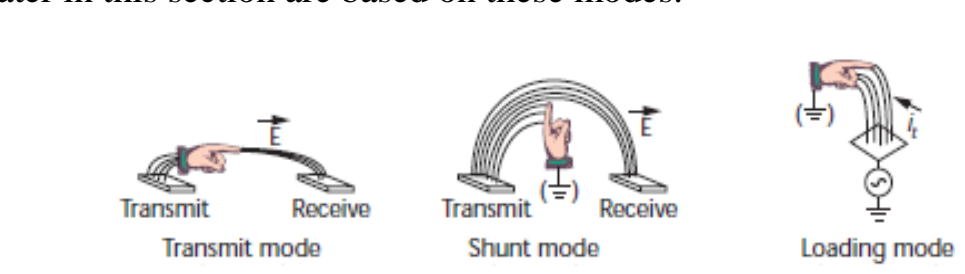

Figure 11. The Operating Modes of Electric Field Localization [58]

With respect to installation, electric fields can propagate through insulators. Sensors can thus be hideden in physical structures, making home electric field positioning systems almost invisible to users. These systems are also relatively inexpensive, as electrodes can be manufactured from relatively cheap materials such as copper foil. However, installation can be ratherarduous.

In the following sub-sections, actual applications implemented based on the electric field positioning, are discussed.

\subsection{TileTrack}

TileTrack [59] operates by measuring the capacitance between floor tiles and a receiving electrode. To prevent stray capacitances formed with the environment from affecting the results, this system uses the human transmitter mode. One can easily transfer the system to a new location, as it requires only a minor recalibration after reassembly. 


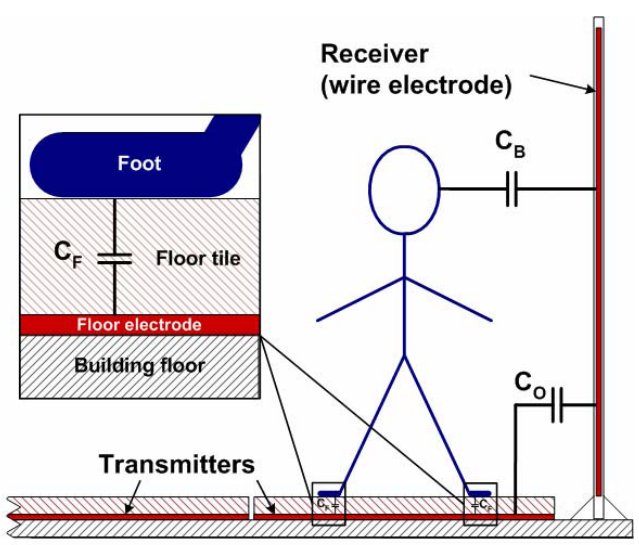

Figure 12. The Capacitance Model of the System [60]

The system operates according to the capacitance model shown in Figure $12 . \mathrm{C}_{\mathrm{O}}$ is the constant offset capacitance between the electrodes without a person present. $C_{F}$ is the capacitance between a person's feet and the transmiter electrode beneath a floor tile. $\mathrm{C}_{\mathrm{B}}$ is the capacitance between a person's body and the receiving electrode. When a person moves into the tracking area, $\mathrm{C}_{\mathrm{F}}$ and $\mathrm{C}_{\mathrm{B}}$ change. When a person is standing on a tile, $\mathrm{C}_{\mathrm{F}}$ increases and the transmitted signal is coupled to the body. The transmitted signal flows through $C_{B}$ to the receiving electrode, and the system measures this current flow. The system measures the total capacitance, which is the series capacitanee of $\mathrm{C}_{\mathrm{F}}$ and $\mathrm{C}_{\mathrm{B}}$ parallel to $\mathrm{C}_{\mathrm{O}}$, from the measured current. The system continuously scans the floor tiles one at a time and measures the total capacitance between the tile in question and the receiving electrode. It determines the user's location by comparing the measured capacitance values to the calibration values. This process uses a $32 \mathrm{kHz}$ measurement frequency the frequency at which the human body acts as an almost perfect conductor

The demo platform used $960 \times 60 \mathrm{~cm}$ interlocking floor tiles and $2430 \times 30 \mathrm{~cm}$ interlocking floor tiles to create $3.0 \times 1.8 \mathrm{~m}$ floor. The transmitting electrodes, made of thin copper plates, were glued to the bottom surface of the tiles. The demo tested different kinds of wires, metal sheets, and a silyer-plated textile shelter as receiver electrodes. The demo platform achieved an accuracy of $15 \mathrm{~cm}$ for standing persons and $41 \mathrm{~cm}$ for walking persons. The system was able totrack multiple persons, if those persons stayed at least one tile away from one another. In later studies, Valtonen et al., [61, 62] proved that this localization technology could also determine a person's posture and height.

For this type of system, the construction costs are quite low: approximately $€ 16 \mathrm{per}^{2}$ for electronics and cabling and $€ 4$ per $\mathrm{m}^{2}$ for electrodes [63]. However, the installation is arduous if the transmitter electrodes are installed under the floor surface.

\subsection{Electric Field Resonance Coupling}

The system proposed in [64] and [65] resembles the TileTrack, but uses electric field resonance coupling. In practice, this means that the resonance that occurs inside a person's body amplifies the electric field transmitted to that person by capacitive coupling between the transmitter and the person's body. The system generates this resonance by using the resonant frequency of an ungrounded person $(70 \mathrm{MHz})$ as its measurement signal frequency [65]. The system can achieve a wider sensing range and better accuracy by using this resonant frequency. Simulation results indicated that this system can achieve an accuracy of $5 \mathrm{~cm}$. 


\subsection{ELSI}

The Electric Sensors with Intelligence (ELSI) system is a location system that operates in the loading mode; it measures the capacitance between a transmitter and the ground [66]. The measurement signal is fed to a single transmitter at a time; all the other sensors are grounded. If there is a conductive object, such as a person, near the actuated electrode, the displacement current flowing from the object through the air to the surrounding grounded sensors increases. The system measures the displacement current from each sensor and uses the current and the physical location of the sensors to determine the person's position. Figure 13 presents the ELSI measurement principle.

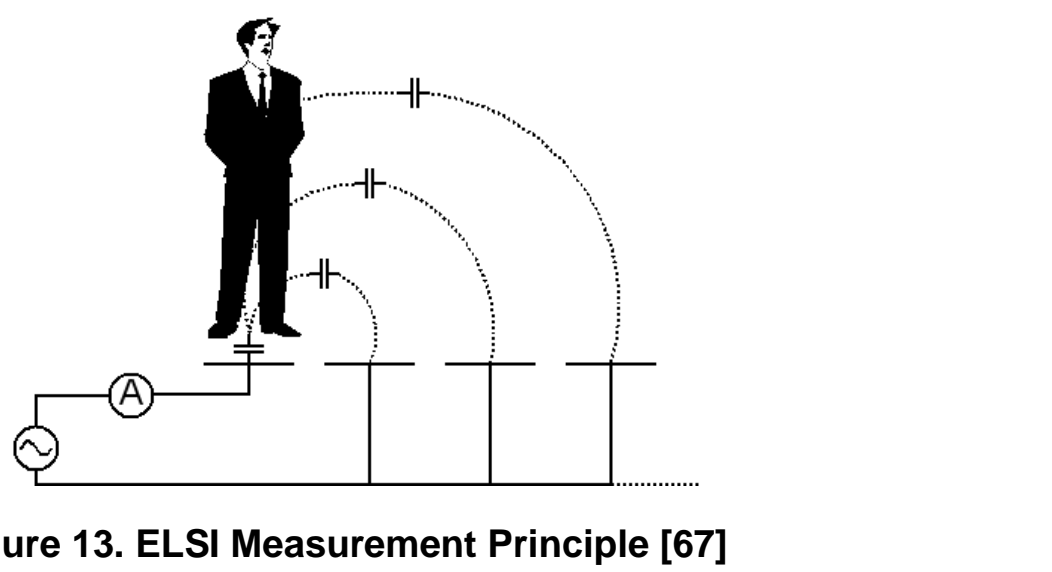

The electrodes are $30 \times 30 \mathrm{~cm}$ metalthick-film squares that are installed under the floor surface, so the system is completely undetectable. The size of the covered floor area is scalable, but the pilot platform described in [68] was $4.5 \times 4.0 \mathrm{~m}$. This pilot achieved a mean positioning error of $21 \mathrm{~cm}$ for five walking persons.

Further development of the ELSI system has produced systems that are suitable for use in health care environments and are able to detect if a person falls [69, 70]. ELSI systems are now commercially available and in use in nursing homes.

Construction and installation costs for ELSI systems are very similar to those of TileTrack systems. The cost of electronics and electrodes is quite low, but the installation is arduous and expensive, especially if installed in an existing home [69].

\section{Infrastructyre-mediated Sensing}

Infrastructure-mediated location sensing uses pre-existing structures in a building for positioning purposes. These structures can include air conditioning channels [71], electrical wires and switches [72], and water pipes and plumbing [73]. This type of system does not require the installation of new sensing infrastructure in a home. Hence, it is easy to install and maintain and usually inexpensive and aesthetically pleasing. However, the location resolution of infrastructure-mediated location sensing systems is low compared to other positioning systems.

\subsection{Air Pressure Location Sensing}

According to Patel et al.'s, [71] research, the pressure differential between the supply and return chambers of a mechanical ventilation system's main unit changes when people move around in an apartment. Pressure sensors installed on the air filter in a ventilation system's 
main unit can measure this pressure differential, also known as static air pressure. The sensors are connected to a computer that performs the classification function. No other devices are required, so installation is easy.

The positioning system detects when an internal door is opened or closed and when a person walks through a doorway. Opening or closing a specific door or walking through a specific doorway will generate a unique change in the static air pressure. Before operation, the system requires a training phase, during which the system learns which door or doorway causes which size of change. Also, the system can still detect changes in the static air pressure when the mechanical ventilation system is turned off, but its activity classification accuracy deteriorates significantly.

When tested in four houses, the system correctly classified door transition events about $75 \%$ of the time and people transition events about $64 \%$ of the time. The accuracy depended heavily on the structure and location of the ventilation system. For instance, if an air vent was a significant distance from an interior door, the accuracy of the events related to that door or doorway were lower.

By combining door and people transition events, the system can provide reasonable predictions about which room a user is in. For many applications, there is no need to know the user's more precise location. However, the pilot platform described in [71] did not address multiple simultaneous events, which systems will need to interpret in real environments.

As this air pressure location sensing system uses pre-existing ventilation infrastructure and requires only one sensing unit, the installation and manufacturing costs are low. The sensing unit costs about $€ 80$ at low volumes. The sys em is also completely invisible to users.

\subsection{Residential Power Line Location Sensing}

Another research conducted by Patel et al., [72] exploited the observation that electrical switches and devices create electrical noises on residential power lines. Separate devices and switches produce dissimilar noises; even wo similar light switches can produce dissimilar noises. Accordingly, one can determine which device or switch is turned on or off by measuring the noise.For measurement, the researchers used one measuring module that was plugged into an electrical outlet in a house. They connected the measuring module to a computer that analysed the noise and inferred the source.

This system is more suifable for context or activity detection than location tracking. However, one can still use this system to determine an inhabitant's position. For example, if the system detects that the bedroom lights were turned on, it can infer that the inhabitant has just entered the bedroon

Patel et al., tes ed this system in six houses and detected 19 separate devices. The accuracy of electrical event classification was about $90 \%$. In one house, a background noise interfered with the classification. The age, condition and structure of the houses' electrical installations also had a detectable effect on the system's accuracy.

The system requires a learning period before operation, and can only detect fixed electrical device. However, installation is extremely effortless, and manufacturing costs are low.

One alternative is a system that recognises electrical devices by measuring the electric current. This system requires the installation of a current sensor near every appliance. This provides precise results, but installation is very laborious [18].

\subsection{Location Tracking by Water Usage}

Rather than detecting air pressure or electrical activity, Fogarty and Hudson's [73] infrastructure-mediated location sensing system identifies activities that use water. As these 
activities usually occur in specific locations in a home, this system can also identify the user's location.

In practice, the system requires the installation of a few microphone sensors at critical locations in a home's water distribution infrastructure. The system uses the water usage patterns that the sensors identify to determine which activities are occurring.

The pilot platform implemented in the study reliably identified the activities of six sources: washing machine, dishwasher, shower, toilet, bathroom sink, and kitchen sink. The identification accuracy was almost $100 \%$ for washing machine and dishwasher activity and over $90 \%$ for shower and toilet activity. However, the accuracy for sink use fell between 55 and $88 \%$. The pilot platform used four sensors and a laptop computer that collected data from the sensors and ran the pattern-based recognition algorithm.

This system requires long timescales for event detection. For example, the system might require a 10 -second sample before it can accurately conclude whether the kitchen sink of the bathroom sink is in use. This delay naturally increases the chance of overlapping events, which leads to worse accuracy.

The presented system is very inexpensive and easy to install, as it equires only a few sensors. However, it provides location information only when the user is using water, so it is more of an activity recognition system than a location tracking system.

\section{Radio Frequency}

Radio frequency is a rate of oscillation in the range of $3 \mathrm{kHz}-300 \mathrm{GHz}$. Several RF technologies, including Bluetooth, RFID, WiFi, and Doppler radar, have been used for positioning. These RF solutions usually use TOF of received signal strength indicator (RSSI) as measurement signals [74]. The following sections will discuss Wi-Fi and Doppler radar. Bluetooth and RFID solutions requie users to earry devices with them, so they are beyond the scope of this paper.

\subsection{Wireless Networks}

Wireless network localization systems that require users to carry tags with them have been available for decades However, oussef et al., [2] have developed a device-free RF system. They noticed that the human body acts as an absorber and attenuates wireless signals. By measuring the signal strength or TOF of wireless signals, an RF system can detect changes in an environment and correlate them to a person's location. One could possibly use already installed Wi-Fi networks for this purpose [75].

Youssef et al.'s, pilot system used signal transmitters, which were normal Wi-Fi access points, monitoring points, which could be any device that is capable of receiving a Wi-Fi signal, and an application server. They used an $802.1 \mathrm{lb}$ environment, which runs at the 2.4 $\mathrm{GHz}$ frequency range. They selected the RSSI provided by the access points as a measurement signal. Their pilot setup used a $5.0 \times 5.0 \mathrm{~m}$ area with two access points and two monitoring points.

Before operation, this system must learn the signal strengths at all locations in the area of interest when there is no human presence. The system uses this signal strength information to create a radio map. However, the multipath effect and other phenomena that occur in indoor environments can interfere with the construction of a radio map. In its normal operating mode, the system compares the received signal strength values to the values stored in the radio map. This is known as the fingerprinting method [76].

The average accuracy achieved in a controlled laboratory environment was approximately $15 \mathrm{~cm}$. In real environments, the accuracy is worse. For example, Seifeldin and Youssef [77] 
installed this system in the main entrance and corridors of a real building using three access points and two monitoring points. In this arrangement, the positioning area was about $300 \mathrm{~m}^{2}$. The median distance error was $6.7 \mathrm{~m}$. In [78], the authors continued working on the system's positioning algorithms and achieved a median distance error of $1.8 \mathrm{~m}$ with the same setup.

This system can only track one person at a time. The researchers in [79] realised that the physical configuration of the system, meaning the placement of the monitoring and access points, affects the system's accuracy remarkably. One can achieve the best accuracy by positioning the monitoring and access points so that a person's movement in the area directly affects the lines of sight between the points.

\subsection{Doppler Radar}

The Doppler effects occurs when a transmitter moves relative to a receiver. The transmitted signal is squeezed as the transmitter approaches the receiver, and the frequency of the transmitted signal rises. Researchers mostly discuss the Doppler effect in relation to acoustics, but the concept applies to any kind of wave propagation [80].

Speed measurement with radar is based on the Doppler Effect. The radar transmits a signal with a known frequency; the target reflects this signal back to the radar, and the system measures the frequency of the returned signal. The difference between the frequency of the returned signal and that of the transmitted signal is proportional to the velocity of the target [81].

When a sensor is used to receive a frequency that varies wh the due to the Doppler Effect, the data creates a Doppler curve. Figure 14 displays the Doppler curve of a passing object. One can estimate the object's dis ance and velocily based on the shape of the Doppler curve [80]. This is the idea behind Doppler localization.

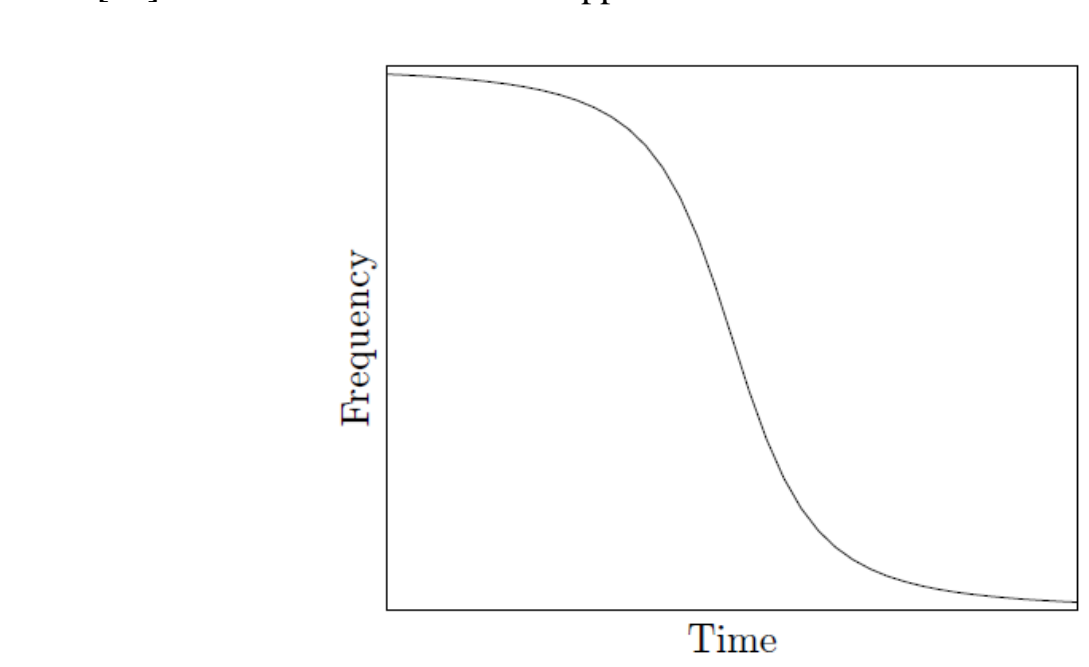

Figure 14. Doppler Curve [79]

Lin et al., [82-84] have researched how to use Doppler radar as a tracking system. However, their studies have focused more on detecting human presence and identifying different types of movements, such as the swinging of arms and legs, instead of defining a person's location.

As it can detect the movement of body parts, Doppler radar can identify a user's activity in many cases. Moreover, as Doppler radar is capable of through-wall tracking, law enforcement 
and military applications regularly employ it. However, as Doppler radar is only able to track moving objects, it cannot be used to track a person who is standing still.

\section{Forthcoming Technologies}

This section presents technologies, systems, and ideas that could be used for device-free indoor positioning but are not yet being actively studied.

\subsection{Optical Sensors}

Optical sensors could also position humans. The positioning could employ two modes: the reflective mode and the shadow mode. In the reflective mode, the target reflects a light signal, and in the shadow mode, the target prevents a light signal from reaching the sensor.

For instance, LiteFoot is an optical system that tracks dancers' steps and can be used in dance training. The system uses a matrix of optical proximity sensors [85]. Dance steps can be as rapid as 30 steps per second, so the system's response time must be fast. The system therefore scans the sensors every $10 \mathrm{~ms}$.

The pilot platform was $1.8 \times 1.8 \mathrm{~m}$ and had 1936 sensors. The researchers tested the system in both operating modes [86]. In the reflective mode, the sensors emitted light and detected the light reflected back by the dancers' soles. In the shadoy mode, the floor was illuminated from above and footsteps stopped the light from reaching the sensors. The achieved accuracy was high, about $40 \mathrm{~mm}$, and identical in both $\mathrm{m}$ odes.

\subsection{Carbon Dioxide Sensors}

Systems could also measure the amount of carbon dioxide in the air to position a person. As [87] explains, the carbon dioxide concentration near a person is substantially higher than elsewhere. So far, systems have used carbon dioxide sensors to detect human presence [30], [34]. However, no actual positioning systens that use this approach have been developed.

\subsection{Detection of Vital Functions}

Finally, researchers could de elop positioning systems that observe vital functions. For instance, in [88], Zakrzewski et al., describe the use of high-frequency radar for non-contact heart and respiration rate measurement. As this system is able to detect respiration and heartbeat remotely, its teconology could be applied to position human beings.

\section{Discussion and Conclusion}

In intelligent environments, user location information is vital. Moreover, especially when used in homes, a positioning system must be passive, device-free, and unobtrusive. This paper has presented the main technologies that can be used in such positioning.

The variety of the features available in positioning systems is wide, and every system has its own pros and cons. Whereas one system may provide more accurate location data, another system may be cheaper or easier to install. Table 1 compares the price, ease of installation, accuracy, and obtrusiveness of the positioning technologies presented in this paper.

The discussed positioning systems are purpose-built; none can be easily extended for use in all cases. The optimal option depends heavily on the requirements set by the application that uses the position data. Other conditions, such as the required degree of accuracy, whether the positioning framework can be installed during the construction of the home, and the funds available, can also significantly influence selection. 
Technically, the best solution is usually a combination of two or more technologies. For example, [89] used thermal infrared sensors in conjunction with infrastructure-mediated sensing to follow several people simultaneously, whereas [12] used Doppler radar and pressure sensors in tandem. The most suitable combination of technologies depends entirely on the case.

Research in this area continues. In the near future, cheaper and more accurate systems will be available and researchers will publish entirely new solutions.

Table 1. Characteristics of the Discussed Positioning Technologies

\begin{tabular}{|c|c|c|c|c|}
\hline Technology & Price & Ease of Installation & Accuracy & $\begin{array}{l}\text { Obtrusivenes } \\
\text { s }\end{array}$ \\
\hline Pressure sensors & $\begin{array}{l}\text { Expensive for large areas, as } \\
\text { accuracy requires several } \\
\text { sensors. }\end{array}$ & $\begin{array}{l}\text { Laborious. Sensors are usually } \\
\text { installed under the floor surface. }\end{array}$ & $5 \mathrm{~cm}$ & \\
\hline $\begin{array}{c}\text { Thermal infrared } \\
\text { sensors }\end{array}$ & $\begin{array}{l}\text { Pyroelectric and thermopile } \\
\text { applications are inexpensive. } \\
\text { Microbolometer-based } \\
\text { cameras are expensive. }\end{array}$ & $\begin{array}{l}\text { Moderate. Ease depends on the } \\
\text { number of sensing elements used. }\end{array}$ & & le. \\
\hline $\begin{array}{c}\text { Sound source } \\
\text { localization }\end{array}$ & $\begin{array}{l}\text { A microphone array is needed, } \\
\text { but relatively inexpensive } \\
\text { miniature microphones can be } \\
\text { used. }\end{array}$ & $\begin{array}{c}\text { Moderate. At least three } \\
\text { microphones are needed. However, } \\
\text { accuracy increases as the number } \\
\text { of microphones increases. }\end{array}$ & & $\begin{array}{c}\text { Almost invisible. } \\
\text { Microphones can } \\
\text { be hidden, e.g. in } \\
\text { picture frames. }\end{array}$ \\
\hline Ultrasound & $\begin{array}{c}\text { Expensive for large areas due } \\
\text { to the number of sensors } \\
\text { required. }\end{array}$ & Laborious. Several sensors are & $5-10 \mathrm{~cm}$ & Invisible. \\
\hline Electric field & About $€ 20$ per $\mathrm{m}^{2}$. & $\begin{array}{l}\text { This system usually } \\
\text { he installation of } \\
\text { der the floor surface } \\
\text { ne ceiling. }\end{array}$ & $15-30 \mathrm{~cm}$ & $\begin{array}{l}\text { Invisible. } \\
\text { Electrodes can be } \\
\text { installed under } \\
\text { the floor surface } \\
\text { and in ceilings. }\end{array}$ \\
\hline $\begin{array}{l}\text { Infrastructure- } \\
\text { mediated sensing }\end{array}$ & $\begin{array}{c}\text { Hundreds of euros per } \\
\text { household }\end{array}$ & $\begin{array}{l}\text { Moderately easy. This system } \\
\text { usually only requires the } \\
\text { installation of a couple of sensors. }\end{array}$ & Room & $\begin{array}{l}\text { Invisible. Sensors } \\
\text { can be installed } \\
\text { outside of the } \\
\text { living area, in the } \\
\text { basement or in } \\
\text { the loft. }\end{array}$ \\
\hline Radio frequency & & Easy. & $1 \mathrm{~m}$ & Almost invisible. \\
\hline
\end{tabular}

[1] F. B. Elbahhar and A. Rivenq, "New Approach of Indoor and Outdoor Localization Systems", Rijeka: Intech, (2012).

[2] M. Youssef, M. Mah and A. Agrawala, "Challenges: Device-free passive localization for wireless environments", Proc. 13th Ann. Acm Int. Conf. Mobile Computing and Networking, (2007), pp. 222-229.

[3] M. Harville "Stereo person tracking with adaptive plan-view templates of height and occupancy statistics", Image Vis on Comput., vol. 22, no. 2, (2004), pp. 127-142.

[4] J. Krumm, S. Harris, B. Meyers, B. Brumitt, M. Hale and S. Shafer, "Multi-camera multi-person tracking for EasyLiving", Proc. 3rd IEEE Int. Workshop Visual Surveillance, (2000), pp. 3-10.

[5] R. Hunter, "World without Secrets: Business, Crime, and Privacy in the Age of Ubiquitous Computing", New York: John Wiley, (2002).

[6] E. M. Tapia, S. S. Intille and K. Larson, "Activity recognition in the home using simple and ubiquitous sensors”, Lecture Notes in Comput. Sci., vol. 3001, (2004), pp. 158-175.

[7] L. Middleton, A. A. Buss, A. Bazin and M. S. Nixon, "A floor sensor system for gait recognition", 4th IEEE Workshop Automatic Identification Advanced Technologies, (2005), pp. 171-176.

[8] R. J. Orr and G. D. Abowd, "The smart floor: a mechanism for natural user identification and tracking", Extended Abstracts Human Factors Computing Syst., (2000), pp. 275-276.

[9] S. Pirttikangas, J. Suutala, J. Riekki and J. Röning, "Footstep identification from pressure signals using hidden markov models", Finnish Signal Process. Symp., (2003), pp. 124-128. 
[10] M. D. Addlesee, A. Jones, F. Livesey and F. Samaria, "The ORL active floor", IEEE Pers. Commun., vol. 4, no. 5, (1997), pp. 35-41.

[11] A. Schmidt, M. Strohbach, K. Van Laerhoven, A. Friday and H. W. Gellersen, "Context acquisition based on load sensing", UbiComp 2002: Ubiquitous Computing, (2002), pp. 161-192.

[12] J. Paradiso, C. Abler, K. Hsiao and M. Reynolds, "The magic carpet: Physical sensing for immersive environments", CHI '97 Extended Abstracts Human Factors Computing Syst., (1997), pp. 277-278.

[13] M. Paajanen, J. Lekkala and K. Kirjavainen, "ElectroMechanical Film (EMFi) - A new multipurpose electret material", Sens Actuators A Phys, vol. 84, no. 1, (2000), pp. 95-102.

[14] B. Richardson, K. Leydon, M. Fernstrom and J. A. Paradiso, "Z-Tiles: building blocks for modular, pressuresensing floorspaces", CHI'04 Extended Abstracts Human Factors Computing Syst., (2004), pp. 1529-1532.

[15] D. Savio and T. Ludwig, "Smart carpet: A footstep tracking interface", 21st Int. Conf. Advanced Inform. Networking and Applicat. Workshops/Symp., (2007), pp. 754-760.

[16] D. Hauschildt and N. Kirchhof, "Advances in thermal infrared localization: Challenges and solutions", Int. Conf. Indoor Positioning and Indoor Navigation, (2010), pp. 1-8.

[17] M. Tkacova, R. Hudak, J. Zivcak and J. Sidun, "Thermographic atlas of the human body", 15th LEEE Intt. Conf. Intelligent Eng. Syst., (2011), pp. 427-429.

[18] E. M. Tapia, S. Intille, L. Lopez and K. Larson, "The design of a portable kit of wireless sensors for naturalistic data collection", Pervasive, (2006), vol. 3968, pp. 117-134.

[19] M. Shankar, J. B. Burchett, Q. Hao, B. D. Guenther and D. J. Brady, "Human-racking systems using pyroelectric infrared detectors", Optical Eng., vol. 45, no. 10, (2006). pp 106401-106401-10.

[20] A. R. Kaushik and B. G. Celler, "Characterization of passive infrared sensors for monitoring occupancy pattern”, 28th Ann. Int. Conf. Eng. Medicine and Biology Soc., (2006), pp. 5257-5260.

[21] J. Kemper and H. Linde, "Challenges of passive infrared indoor localization", 5th Workshop Positioning, Navigation and Communication, (2008), pp. 63-70.

[22] D. Olmeda, A. de la Escalera and J. M. Armingol, "Contrast invariant features for human detection in far infrared images", Intelligent Vehicles Symp. (IV), (2012), pp. 117-122.

[23] D. H. Do, T. H. Riehle, R. Solinsky, P. Assad-Lamouki, C. T. Hillesheim, T. Velie and G. J. Seifert, "Resolving subjects and measuring observer/subject distances with a thermal tactile imager", Proc. Ann. Int. Conf. IEEE Eng. Medicine and Biology Soc., (2008), pp $4302-4305$.

[24] Viper Technologies, RAZ-iR Mini Thermal Solution Kit http://www.pvs4.com. [Online]. Available: http://www.pvs4.com/RAZ-IR.htm Aceessed: (2013) May 11.

[25] D. Denison, M. Knotts, H. Hayden, S. Young andy. Tsukruk, "Influence of micro-Golay cell cavity diameter on millimeter-wave detectron sensitivity", Proc. $36^{\text {th }}$ Int. Conf. Infrared, Millimeter and Terahertz Waves, (2011), pp. 1-2.

[26] J. L. Honorato, I. Spiniak and M. Torres-Torriti, "Human detection using thermopiles", Robotic Symp., (2008), pp. 151-157.

[27] Z. Zhang, X. Gao, Biswas and J K.Wu, "Moving targets detection and localization in passive infrared sensor networks", 10th Int. Conf. In form. Fusion, (2007), pp. 1-6.

[28] N. Yoshiike, K. Morinaka, K. Hashimoto, M. Kawaguri and S. Tanaka, "360 direction type human information sensor", Sensôrs and Actuators A: Physical, vol. 77, no. 3, (1999), pp. 199-208.

[29] P. Wu and F. Li, "The py roelectric sensor based system: Human tracking and self-calibration scheme", Int. Conf. Inform. Scie. and Technology, (2012), pp. 839-846.

[30] Z. Han, R. X. Gao-an Z.' Fan, "Occupancy and indoor environment quality sensing for smart buildings", Instrumentation and Measurement Technology Conf., (2012), pp. 882-887.

[31] D. Hauschildt and N. Kirchhof, "Improving indoor position estimation by combining active TDOA ultrasound and passive thermal infrared localization", 8th Workshop Positioning Navigation and Communication, (2011), pp. 94-99.

[32] X. Zhou, Q. Hao and H. Fei, "1-bit walker recognition with distributed binary pyroelectric sensors", IEEE Conf. Multisensor Fusion and Integration Intelligent Syst., (2010), pp. 168-173.

[33] G. Chetty, "Comparative evaluation of two multisensory video surveillance techniques for pedestrian tracking”, Proc. $2^{\text {nd }}$ Int. Conf. Signal Process. and Commun. Syst., (2008), pp. 1-6.

[34] H. Farhat, E. Bazin, S. Haese and G. E. Zein, "An infrared thermal image acquisition system for intra-vehicle applications", 11th Int. Conf. Telecommun., (2011), pp. 426-430.

[35] G. Monaci and A. Pandharipande, "Indoor user zoning and tracking in passive infrared sensing systems", Proc. 20th European Signal Process. Conf., (2012), pp. 1089-1093.

[36] Q. Sun, F. Hu and Q. Hao, "Context awareness emergence for distributed binary pyroelectric sensors", IEEE Int. Conf. Multisensor Fusion and Integration, (2010), pp. 5-7.

[37] J. Kemper and D. Hauschildt, "Passive infrared localization with a probability hypothesis density filter", 7th Workshop Positioning, Navigation and Communication, (2010), pp. 68-76. 
[38] X. Bian, J. M. Rehg and G. D. Abowd, "Sound Source localization in domestic environment", GVU Center, Atlanta, GA, Tech. Rep., (2004).

[39] M. Mandlik, Z. Nemec and R. Dolecek, "Real-time sound source localization", 13th Int. Radar Symp., (2012), pp. 322-325.

[40] M. S. Brandstein, "A framework for speech source localization using sensor arrays", Ph.D. dissertation, Brown Univ., Providence, RI, (1995).

[41] J. M. Valin, F. Michaud, B. Hadjou and J. Rouat, "Localization of simultaneous moving sound sources for mobile robot using a frequency-domain steered beamformer approach", Robotics and Automation, (2004), pp. 1033-1038.

[42] J. Benesty, "Adaptive eigenvalue decomposition algorithm for passive acoustic source localization", J. Acoustical Soc. of America, vol. 107, vo. 1, (2000), pp. 384-391.

[43] X. Bian, G. Abowd and J. Rehg, "Using sound source localization in a home environment", Pervasive Computing, ser. Lecture Notes in Computer Science, H. Gellersen, R. Want, and A. Schmidt, Eds. Springer, Berlin, (2005), pp. 19-36.

[44] M. Omologo and P. Svaizer, "Use of the crosspower-spectrum phase in acoustic event location", IEEEE Trans. Speech Audio Process., vol. 5, no. 3, (1997), pp. 288-292.

[45] M. Omologo and P. Svaizer, "Acoustic event localization using a crosspower-spectrum phase based technique", IEEE Int. Conf. Acoust., Speech, and Signal Process, vol. 2, (1994), pp. II/273-II/276.

[46] P. Pertilä, T. Korhonen, T. Pirinen and M. Parviainen, "TUT acoustic sôurce tracking system 2006", Lecture Notes Computer Sci., Multimodal Techniques Perception Humans, Southampton, (2007), pp. 127-136.

[47] P. Pertilä and M. Parviainen, "Robust speaker localization in meeting room domaiv", IEEE Int. Conf. Acoust., Speech and Signal Process, (2007), pp. IV497-IV500.

[48] T. Korhonen and P. Pertilä, "TUT acoustic source tracking system 2007”, Multimodal Technologies Perception Humans. Int. Evaluation Workshops CLEAR 2007 and RT 2007, Baltimore, MD, (2008), pp. 104-112.

[49] S. Kagami, H. Mizoguchi, Y. Tamai and T. Kanade "Microphone array for 2D sound localization and capture, Experimental Robotics IX, vol. 21, (2006), pp. 45-54.

[50] M. Turqueti, J. Saniie and E. Oruklu, "Scalable acoustic imaging platform using MEMS array", IEEE Int. Conf. Electro/Inform. Technology, (2010) p. 1.4.

[51] M. Shoji, "Passive acoustic sensing of walking", 5th Int Conf. Intelligent Sensors, Sensor Networks and Inform. Process, (2009), pp. 219-224.

[52] S. Holm and C. C. Nilsen, "Robust ultrasonic indoor positioning using transmitter arrays", Int. Conf. Indoor Positioning and Indoor Navigation, (2010), p

[53] Y. Nishida, T. Hori, S. Marakami, and H. Mizoguchi, Minimally privacy-violative system for locating human by ultrasonic radar enbedded on ceiling", IEEE Int. Conf. Syst., Man and Cybern. vol. 2, (2004), pp. 1549-1554.

[54] M. U. H. Siddique, "Ultrasonic radan and its applications", Proc. 9th WSEAS Int. Conf. Appl. Informatics and Commun., (2009), pp. 225-231.

[55] T. Hori and Y. Nishida, "Ultrasonic sensors for the elderly and caregivers in a nursing home", Proc. 7th Int. Conf. Enterprise Inform. Syst (2005), pp. 110-115.

[56] Y. Nishida, S.Murakami, T. Hori and H. Mizoguchi, "Minimally privacy-violative human location sensor by ultrasonic radar embedaed on ceiling", Proc. IEEE Sensors, (2004), pp. 433-436.

[57] T. G. Zimmerman J. R Smith, J. A. Paradiso, D. Allport and N. Gershenfeld, "Applying electric field sensing to human-computer interfaces", Proc. SIGCHI Conf. Human Factors Computing Syst., (1995), pp. 280-287.

[58] J. Smith, T. White, C. Dodge, J. Paradiso, N. Gershenfeld and D. Allport, Electric field sensing for graphical interfaces Comput. Graph. and Applicat., vol. 18, no. 3, (1998), pp. 54-60.

[59] M. Valtonen, J. Mäentausta and J. Vanhala, "TileTrack: Capacitive human tracking using floor tiles", 7th Ann. HEEE Int. Conf. Pervasive Computing and Commun., (2009), pp. 31-40.

[60] M Valtonen and J. Vanhala, "Human tracking using electric fields", 7th Ann. IEEE Int. Conf. Pervasive Computing and Commun., (2009), pp. 354-356.

[61] M. Valtonen, L. Kaila, J. Mäentausta and J. Vanhala, "Unobtrusive human height and posture recognition with a capacitive sensor", Ambient Intell. and Smart Environ., vol. 3, no. 43, (2011), pp. 305-332.

[62] M. Valtonen, H. Raula and J. Vanhala, "Human body tracking with electric field ranging", 14th Int. Academic MindTrek Conf., (2010), pp. 183-186.

[63] M. Valtonen, "Technologies for Smart Environments: Capacitive User Tracking and Proactive Fuzzy Control", Ph.D. dissertation, Department of Electronics, Tampere Univ. of Technology, Tampere, Finland, (2012). 
[64] S. Ajisaka, S. Nakamura, K. Takiguchi, A. Hirose and H. Hashimoto, "Human body position estimation system using electric field resonance coupling”, Proc. Int. Conf. Control Automation and Syst., (2010), pp. 119-123.

[65] S. Nakamura, S. Ajisaka, K. Takiguchi, A. Hirose and H. Hashimoto, "Electric-field resonance coupling between human and transmitter for human position estimation system", Int. Conf. Control, Automation and Syst., (2010), pp. 109-114.

[66] A. Ropponen, M. Linnavuo and R. Sepponen, "LF indoor location and identification system", Int. J. Smart Sensing and Intelligent Systems, vol. 2, no. 1, (2009), pp. 94-117.

[67] H. Rimminen, M. Linnavuo and R. Sepponen, "Human tracking using near field imaging", 2nd Int. Conf. Pervasive Computing Technologies Healthcare, (2008), pp. 148-151.

[68] H. Rimminen, J. Lindström and R. Sepponen, "Positioning accuracy and multi-target separation with a human tracking system using near field imaging”, Int. J. on Smart Sensing and Intelligent Syst., vol. 2, pp. 156-175, (2009).

[69] A. Ropponen, H. Rimminen and R. Sepponen, "Robust system for indoor localisation and identification for the health care environment", Wireless Pers Commun, vol. 59, no. 1, (2011), pp. 57-71.

[70] H. Rimminen, J. Lindstrom, M. Linnavuo and R. Sepponen, "Detection of falls among the elderty by a floor sensor using the electric near field”, IEEE Trans. Inf. Technol. Biomed., vol. 14, no. 6, (2010), pp. 14751476.

[71] S. N. Patel, M. S. Reynolds and G. D. Abowd, "Detecting human movement by differential air pressure sensing in HVAC system ductwork: An exploration in infrastructure mediated sensing", Proc. Int. Conf. on Pervasive Computing, (2008), pp. 1-18.

[72] S. N. Patel, T. Robertson, J. A. Kientz, M. S. Reynolds and G. D. Abowd, At the flick of a switch: Detecting and classifying unique electrical events on the residential power line, Proc. Int. Conf. Ubiquitous Computing, (2007), pp. 271-288.

[73] J. Fogarty, C. Au and S. E. Hudson, "Sensing from the Dasement: A feasibility study of unobtrusive and lowcost home activity recognition", Proc. 19th Ann ACM Symp. User In erface Software and Technology, (2006), pp. 91-100.

[74] P. Vorst, J. Sommer, C: Hoene, P. Schneiden, Q. Weiss, T. Schairer, W. Rosenstiel, A. Zell and G. Carle, Indoor positioning via three different rf technologiês", 4th European Workshop RFID Syst. and Technologies, (2008), pp. 1-10.

[75] M. Moussa and M. Youssef, "Smârt devi es for smart environments: Device-free passive detection in real environments", 7th Ann. IEEE Int. Conf. Pervasive Computing and Commun., (2009), pp. 1-6.

[76] G. Deak, K. Curran and J. Condell, Device-free Passive Localization using RSSI-based Wireless Network Nodes", $11^{\text {th }}$ Ann. PostGradaate Symp. Convergence Telecommun., Networking and Broadcast., (2010), pp. 241-246.

[77] M. Seifeldin and M. Ooussef, "A deterministic large-scale device-free passive localization system for wireless environments Proc. 3rd Int. Conf. Pervasive Technologies Related to Assistive Environments, (2010), pp. 51-59

[78] M. Seifeldin, A Saeed, A. Kosba, A. El-Keyi and M. Youssef, "Nuzzer: A large-scale device-free passive localization system for witelesb ehvironments", IEEE Trans. Mobile Computing, vol. 12, no. 7, (2011), pp. $1321-1334$.

[79] A. E. Kosba, A. Abdelkader and M. Youssef, "Analysis of a device-free passive tracking system in typical wireless environments" 3rd Int. Conf. New Technologies, Mobility and Security, (2009), pp. 1-5.

[80] A. Lehtinen, "Dopple positioning with GPS", M.S. thesis, Department of Electrical Engineering, Tampere Univ. of Technology, Tampere, Finland, (2002).

[81] R. N. Colvell, "Manual of Remote Sensing", Theory, Instruments and Techniques, $2^{\text {nd }}$ ed., Falls Church, VA: Amer. Soc. of Photogrammetry, vol. I, (1983).

[82] S. S. Ran, Y. Li, A. Lin and H. Ling, Doppler-based detection and tracking of humans in indoor en vironments, J. Franklin Inst., vol. 345, no. 6, (2008), pp. 679-699.

[83] S. S.Ram, Y. Li, A. Lin and H. Ling, "Human tracking using Doppler processing and spatial beamforming", IEEE Radar Conf., (2007), pp. 546-551.

[84] A. Lin and H. Ling, "Doppler and direction-of-arrival (DDOA) radar for multiple-mover sensing", IEEE Trans. Aerosp. Electron. Syst., vol. 43, no. 4, (2007), pp. 1496-1509.

[85] M. Fernström and N. Griffith, "Litefoot-Auditory display of footwork", Proc. Int. Conf. Auditory Display, (1998).

[86] N. Griffith and M. Fernström, "LiteFoot: A floor space for recording dance and controlling media", Proc. Int. Comput. Music Conf., (1998), pp. 475-481.

[87] P. Kallioniemi, "KILAVI-sensorisolmun laajentaminen kiinteistöjen valvontaan”, M.S. thesis, Department of Electronics, Tampere Univ. of Technology, Tampere, Finland, (2011). 
[88] M. Zakrzewski, H. Raittinen and J. Vanhala, "Comparison of center estimation algorithms for heart and respiration monitoring with microwave Doppler radar", Sensors J., vol. 12, no. 3, (2012), pp. 627-634.

[89] A. S. Crandall and D. J. Cook, "Coping with multiple residents in a smart environment", J. Ambient Intell. and Smart Environments, vol. 1, no. 4, (2009), pp. 323-334.

\section{Authors}

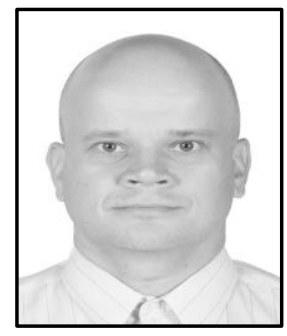

Tero Kivimäki received his Master of Science in 1998 in software engineering and Licentiate in Technology degree in 2004 from Tampere University of Technology. He currently holds a position of a research scientist at Tampere University of Technology, Department of Electronics and Communications Engineering, Personal Electronics Group, and he is currently finalizing his doctoral thesis. His research interests include assisted living, smart environments and ubiquitous computing.

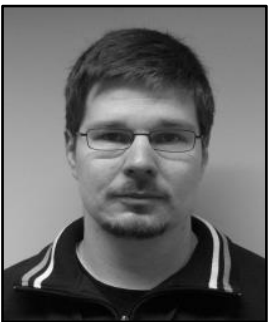

Timo Vuorela received his Master of Science in 2002 in electrical engineering and Doctor of science (Technology) in 2011 from Tampere University of Technology. He is currently working as a postdoctoral researcher at Tampere University of Technology, Department of Electronics and Communiçations Engineering, Personal Electronics Group. His research interests include embedded systems e.g. portable physiological measurement devices and smart clothing.

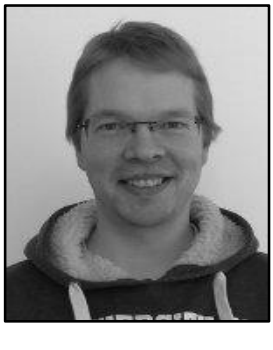

Pekka Peltola received bis Master of Science in 2009 in electronics from Tampere University of Technology. He is currently working on his $P$ CD in Nottingham Geospatial Insitute in Nottingham University. Before that he worked in Tampere University of Technology, Department of Electronics and Communications Engineering, Personal Electronics Group. His research interests include embedded systems, multi sensor indoor navigation and ubiquitous computing.

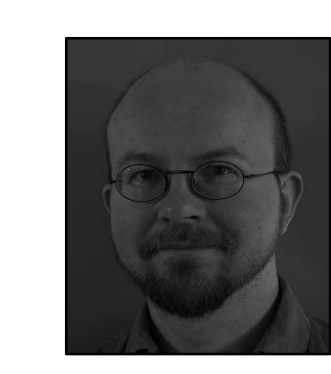

Jukka Vanhala received his Master of Science in 1985, Licentiate in Technology in 1990 and Doctor of Technology in Computer Science in 1998 from Tampere University of Technology. Currently he acts as a professor at the Tampere University of Technology, Department of Electronics and Communications Engineering, being responsible of teaching embedded systems. Vanhala is also head of the Kankaapää Research Unit for Wearable Technology. His research interests include ambient intelligence, smart garments and embedded systems. 
International Journal of Smart Home

Vol.8, No.1 (2014)

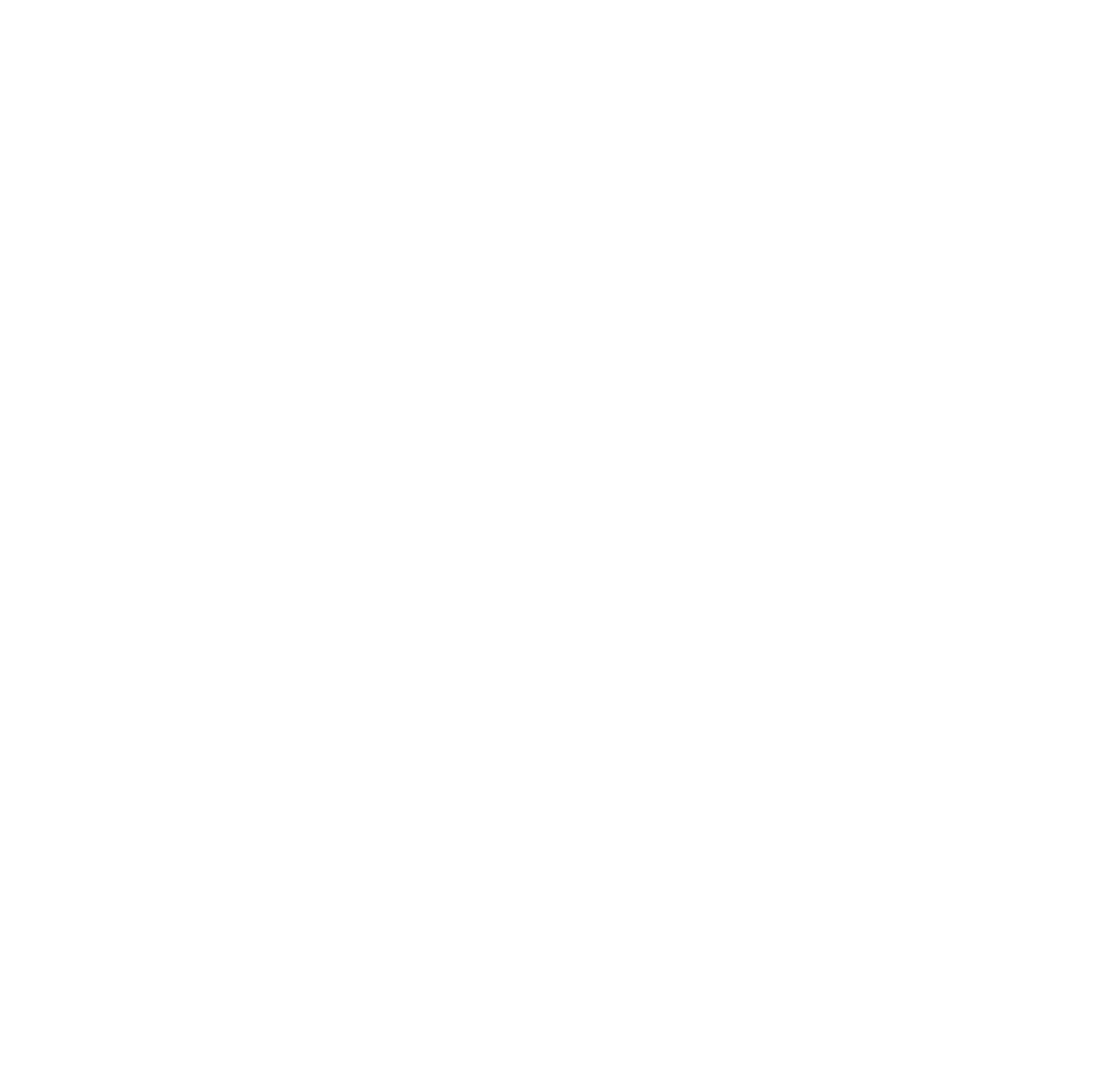

